\title{
Anthropocene Futures and Water Security
}

\section{FRANS BERKHOUT}

Department of Geography, King's College London and Future Earth Programme frans.berkhout@kcl.ac.uk

\section{THE ANTHROPOCENE AND WATER SECURITY}

A central claim about the Anthropocene is that this new epoch, in which people have become the primary geological force, raises profound questions about the sustainability of human development (Crutzen 2002). Human populations have grown dramatically, especially over the past two centuries; these people have grown on average wealthier, drawing on massively greater natural resources and environmental services, including water (Steffen et al. 2011).

A number of 'planetary boundaries' have been defined (Röckstrom et al. 2009), which point to the most urgent dimensions of the global sustainability problems that flow from the scale and scope of human appropriations and interventions in biophysical Earth Systems. These include by now familiar changes and impacts associated with climate change, ozone depletion, biodiversity loss and land-use change, as well as global freshwater use. Röckstrom et al. (2009) suggest using consumptive water run-off (or blue water use) as a proxy for global freshwater use. Assuming an upper limit of $\sim 12500-15000 \mathrm{~km}^{3}$ year ${ }^{-1}$ of accessible blue water resources, they suggest that consumptive uses above a threshold of $4000-6000 \mathrm{~km}^{3}$ year $^{-1}$ would represent a significant risk to ecosystems, moisture feedbacks and freshwater/ocean mixing. Given that consumptive use is now at about $2600 \mathrm{~km}^{3}$ year-1 the authors conclude that there appears to be some room for manoeuvre, although there continues to be a trend of rapidly growing consumptive water use at the global scale.

In addition, a number of other problems associated with access to resources have been pointed to: peak oil; peak phosphorus; and the resilience of ecosystem services (Steffen 2011). Beyond this, there is the growing awareness of 'systemic risks' to global economic, financial and political systems linked to the degradation, failure or transformation of key biophysical and ecological systems. Perhaps one of the most striking claims is that an epoch of relative stability in these systems (the Holocene) has been replaced by a new period of rapid change, instability and continuing transience, with growing risks of thresholds and tipping points (Lenton et al. 2008).

\section{GLOBAL CHALLENGES, GLOBAL RESPONSES?}

An Anthropocene framing of global sustainable development problems seems to invite planetaryscale responses, such as geo-engineering, and appeals for the global governance of planetary boundaries. But there are questions about whether the planetary (or global) scale is really the appropriate scale at which to govern many of the critical global resources and environmental services, including water. Water is typically governed at the level of the river basin and ecosystem. Moreover, while for some global environmental problems, like stratospheric ozone depletion, global governance appears to have been, in large part, successful, there are questions about whether such global coordination can be achieved in other cases. While global governance regimes now exist in many environmental domains, including climate change, achieving an alignment of interests leading to a common understanding of the problem and effective action at the global scale has often proven elusive. Water security emerges at many different and connected scales, from the local to the global. And there are important legal, regulatory and voluntary dimensions of global water governance that contribute to water security across these scales. These include norms about rights to water, technical and other standards for water use and quality, as well as international transfers of knowledge, technology and finance to support water security goals. Nevertheless, a global water governance regime oriented towards delivering a specific planetary boundary seems a far-off prospect. 


\section{ACHIEVING WATER SECURITY IN THE ANTHROPOCENE}

For the time being, the right question to ask is: how will the Anthropocene perspective influence the perceptions, norms, plans and actions of people, organizations and governments? Clearly social science can play a major role here. For the most part, social scientists are cautious in making predictions and forecasts for the future. This is partly because futures, including Anthropocene Futures, will not be universal - just as there are multiple realities in the present, there will be multiple realities in the future - and partly because there remain deep uncertainties about what the future will look and feel like. The future is not a stable object of study - awareness of it leads immediately to changed expectations and behaviour, changing the stream of events that shapes the future. Bearing these profound limitations to all future scenarios in mind, here are some predictions about Anthropocene Futures.

\section{Costs and opportunities}

Both costs and opportunities are presented by the global sustainability problems obtained by the Anthropocene analysis. Costs and opportunities are the drivers of innovation. For instance, water scarcity and insecurity are both a problem and a trigger for technological and behavioural innovations. Growing systemic risks to food security as a result of climate change, growing pressure on global land resources and the desire to protect biodiversity will likewise generate the search for new, more diversified, but intensified global food production systems. Changing relative prices and preferences will change the role of meat in diets in unpredictable directions. Even a looming limit to phosphorus production is likely to lead to innovations in low-P agriculture.

Access to resources is not a static zero-sum game. Relative prices, geopolitics and ingenuity reshape technologies and supply and demand continually. Scarcity and crisis lead to new strategies among producers and preferences among consumers, and this in turn leads to the emergence of new scarcities, crises and innovation in patterns that can only be guessed at. It is true that fossil carbon-based energy has been at the heart of economic development for the past 200 years or more, but if the problems of energy density and storage can be solved in the coming decades, there is no reason to believe that absolute decoupling of carbon from growth will not occur. There is therefore a major research task in seeking to understand not only the connectedness of global change and sustainability problems, but also the interactions shaping social and economic responses.

\section{Useful knowledge}

While there is consensus that in the long run and at the global level, the consequences of scarcity of key resources and transient global environmental systems will be severe, the way in which these costs and opportunities will unfold over the coming decades and in particular places is still not well-established. The Anthropocene perspective, with its emphasis on the global and the long-run, may be an obstacle here. This is not to say that social and economic actors do not act on the longterm - we all save for our pensions, companies invest in infrastructures with lifetimes of many decades - but there is still much to learn about precisely when, where and how serious risks will turn out to be for cities, infrastructures, water services, food security and so on. Bringing the Anthropocene into focus over the coming decades and at spatial and social scales that matter to people remains a formidable analytical task.

\section{Global inequalities}

The costs and opportunities of new planetary risks will be highly unevenly distributed - there will be winners and losers - and this affects the capacity to 'act globally'. Global responses to global risks are most likely when powerful economic and political interests are at stake. Risks tend to be shifted to the weakest and this will continue to be the case, even as more global and connected challenges to sustainable development emerge. Just as global environmental change is an outcome of past inequities of access to natural, economic and human resources, so global environmental 
change has often acted to exacerbate those inequities in access to resources and environmental services. It may even be argued that the greater the intensity of global competition for resources and services, the less likely is international cooperation to achieve their stewardship. The experience of the United Nations Framework Convention on Climate Change may bear this out. A study of the geopolitics of the Anthropocene would seek to understand these dynamics of power and to inform the development of new institutions that can foster cooperation for planetary stewardship.

These inequalities will mean that the capacity of people and organisations to deal with constraints on access to resources and to cope with transient environmental services will continue to vary in the future. Much of this resilience and adaptive capacity will be expressed across social scales, at regional, national and local levels, often down to the level of individuals and households. Economic growth will provide greater capacities, while distributive policies, nationally and internationally, will aim to build capabilities to achieve sustainable development. But there are also likely, perhaps sooner rather than later, to be limits in these capacities to adapt (Dow et al. 2013).

\section{Winners and losers}

Finally, we can predict that there will be multiple Anthropocene futures - it depends on who you are and where you stand. And perhaps this is the most confusing aspect of the idea of the Anthropocene. Tickell (2011) suggests that: '... humans can be regarded, like certain species of ants, as a super-organism'. This is an arresting metaphor because it suggests an emergent property in the global collective action of individuals and societies. But there is unlikely to be a single perspective or consciousness through which to view the predicaments that are presented by the Anthropocene. Short of a real cataclysm, it is likely that 'good' and 'bad' Anthropocenes will continue to exist side-by-side for a long time to come.

\section{SCIENCE FOR THE ANTHROPOCENE}

We are living through a time of great transformations towards sustainability in energy, food, transport and urban systems. The Anthropocene provides one of the underlying narratives propelling these transformations. Such impacts in shaping expectations and rationales - for investment, for regulation, for lifestyles, for a planetary ethics - are hard to measure and disentangle from the many other influences on social action. The role of programmes like Future Earth (www.futureearth.info) will be to continue to support research on the long-run and the global. But we also have a responsibility to do science that connects to the knowledge and actions of social actors as we find them; in the boards of corporations, in government ministries, in households and in civil society. Connecting to these lived futures challenges us to think again about how we pose questions and how we seek to answer them.

\section{REFERENCES}

Crutzen, P.J. (2002) Geology of mankind: The Anthropocene. Nature 415, 23.

Dow, K., et al. (2013) Limits to adaptation. Nature Climate Change 3, 305-307.

Lenton, T.M., et al. (2008) Tipping elements in the Earth's climate system. Proceedings of the National Academy of Sciences $105,1786-1793$.

Rockström, J., et al. (2009) Planetary boundaries: Exploring the safe operating space for humanity. Ecology and Society $14,32$. Available at: www.ecologyandsociety.org/vol14/iss $2 /$ art32/.

Steffen, W., et al. (2011) The Anthropocene: From global change to planetary stewardship. AMBIO 40, 739-761.

Tickell, C. (2011) Societal responses to the Anthropocene. Philosophical Transactions of the Royal Society, London A 369, 926-932.

This paper draws substantially on:

Berkhout, F. (2014) Anthropocene Futures. The Anthropocene Review 1-6, doi:10.1177/2053019614531217. 